\title{
Comparative Study on Hong Kong and Macao and the Mainland College Student Association
}

\author{
Bao-shan $\mathrm{Yu}^{1}$ \& Fen Jiang ${ }^{2}$ \\ ${ }^{1}$ Jinan University, Guangzhou, China \\ ${ }^{2}$ Beijing Institutes of Technology, Zhuhai, China \\ Correspondence: Fen Jiang, Beijing Institutes of Technology, Zhuhai 519088, China. E-mail: \\ xgsfsdhkj@163.com
}

Received: August 30, 2015 Accepted: September 21, $2015 \quad$ Online Published: October 21, 2015

doi:10.5539/ass.v11n26p302 URL: http://dx.doi.org/10.5539/ass.v11n26p302

\begin{abstract}
To strengthen the research on youth work under the new situation, is the inherent requirement of the Communist Youth League to thoroughly implement the spirit of the 17th CPC National Congress, also is urgent need of doing youth work well under the new situation. Student community college students and social relations as a bridge, is the important content of young college students work, learn from each other advanced corporation management experience has important theoretical and practical significance to make the Communist Youth League work in new period. This subject to Hong Kong and Macao and the mainland college students as the research object, by way of comparative study of colleges and universities in mainland students in Hong Kong and Taiwan differences and common function, in order to provide a reference and learning for mainland college student societies.
\end{abstract}

Keywords: college, student Association Hong Kong, Macao and Taiwan, revelation

\section{Introduction}

College Student Association is an important way of quality education and effective way in strengthening the campus culture, improve their overall quality, and guide students to adapt to society, promote student taught employment has played an important role. In a certain sense, the existence of these associations and activities is both objective and rational reflection background, but also to lead a modern academic thinking, scientific thinking and ethics of the "source." Community college students in order to promote China's development, we must actively participate in domestic and international exchanges, study, learn from universities abroad, especially in Hong Kong, Macao and Taiwan advanced experiences and practices for effective research, which grafted into our community college students, the as I used to.

\section{Hong Kong, Macao, Taiwan and the Mainland Before the Development of Community College Students}

\subsection{Hong Kong, Macao and Taiwan Students Associations Overview}

Hong Kong, Macau, Taiwan, due to the different historical backgrounds, different educational development, so three college student groups also showed different characteristics. Hong Kong College Student Association's organizational structure and operational mechanism with mainland universities are quite different, it is not primarily dependent on the administrative funding, but rather self-activity, self-financing, independent community organizations, with high independence. But one thing and the Mainland, Hong Kong is also the main activities of college students rely on student organizations and all levels of society. While many colleges and universities in student societies operate completely independent form, but in practice, the Student Affairs Office Student Association still some degree of guidance, management and supervision, foreign student organizations increased from the Student Affairs Office is responsible for the problem. Hong Kong university student societies are generally operate independently, with separate office, in order to promote student government, the campus goal of governance, internal and actively participate in school governance, and promote students' awareness of and participation in society, co-ordinate student organizations and activities, to provide students welfare, organization of cultural activities. Externally, on behalf of the students to express their views, issued a statement, participation in social affairs.

Cadres of community college students in Hong Kong are usually generated through the campaign, but there are 
some ways through interviews produced. Hong Kong University Students' Union General Council and Executive Committee on behalf of the establishment, and some set up in accordance with the principle of separation of powers, the arbitration will be. Community is an important part of the student union, to accept the leadership representatives. Behalf by the Chairman, Vice Chairman, the Secretariat and a number of standing committees, each representative of the general faculties affiliated to affiliated clubs and societies Halls units assigned, depending on how many places depending on the number of its members, each of which occupies a very strong community weight. Their important duty is to safeguard the interests of students, the students organized activities. Hong Kong University Students' Union affiliated to both affiliated faculty, but also the affiliated societies. Graduate will be different with the Mainland, Hong Kong's affiliation graduate students include various functional departments and graduate associations affiliated to graduate faculty will generally do not, their activities tend to student organizations, the main activities are carried out through the community. Hong Kong university student hostel also has its own student union and community organizations, called the Halls Halls Residents' Association or Union. Halls students, community development in the long term also formed their own characteristics and varying between Halls culture, students can choose according to their own interests for their own hostel. Students and faculty student hostel almost the same position in the Student Union also has its own behalf, Halls student organizations also have a representative will be other agencies and officials, and set up a floor grassroots organizations regularly organize Scotia occasion, sports events between floors. The annual October to March is the student organization when the general election. Formal election by an organization's entire membership suffrage, generally site voting member of the organization, but now many organizations also use a network ballot. Students and community posts campaign in Hong Kong, also known as "the village", "village" is the meaning of the Cabinet.

Hong Kong College Student Association's main source of funding have membership dues, social and alumni donations, student organizations operating and investment income, the school and the SAR Government funds. Some students in Hong Kong as well as cultural associations, sports federations, associations such Society set up in accordance with the student categories Associations, societies need to go to such a category in the first registered before they can once again become the student union affiliated to become affiliated student organizations, hostel boarders will be able to apply for the student Union's resources. Student Union affiliated clubs and societies on offer financial allocations, activities, network services, interest-free loans. School students will also affiliated clubs and associations to review the qualifications and financial condition, including the constitution, membership, institutional settings, activity plan, the validity of the election results and dues payments, financial reporting, student grants, etc. using . Such as Hong Kong Chinese University Student Affairs in a number of student activities offered each semester funds for organizations to apply for their students, including student activities funded Alumni Student Activities Fund and HSBC Hong Kong student activity funds. Funding for Student Union of the Chinese University of Hong Kong under the student body (not including college groups) apply, funding to finance student groups organize more meaningful extracurricular activities, financing activities in the amount of visual significance, size, nature, number of beneficiaries the group to help the healthy development and other factors, depending on the diet group events expenditure not funded. Societies need assistance in the economy, the first to submit a report to the Student Affairs Office applications.

Macau and Hong Kong community college students is similar to student organizations, with their own unique rules and regulations, and management systems clear, clear division of labor, with its comprehensive membership criteria, organizational structure, financial system and the withdrawal mechanism. Macao University Students' Union, for example, by a member of UM Students Conference, Council and Board of Supervisors composed. Member General Assembly is the highest authority of the Council by all the Members, and a bureau. The Chairperson, Vice-Chairman and Secretary of a composition. Consists of over sixty affiliated student organizations, including the Student Union and various community organizations, community organizations directly managed by the students, student organizations whose main academic associations, cultural associations and sports leagues three categories. Academic Council which mainly academic research based, including Chinese Society, Communication Society, Economics Society, English Society and other 14 community organizations, civic associations mainly in the arts, entertainment-based activities, including State Society, Chess Club, the Catholic Alumni Association, Drama Club and other 18 organizations, and sports leagues are mainly in sports, physical fitness activities, mainly with Athletics Club, football Club, Dragon Boat Club, martial Arts Club and fitness will be other types. Macau University of Science and a specialty societies foreign student club, which is composed of non-local students by the students, is Australia's largest HKUST students will be subordinate, and to serve non-local students for the purpose of student organizations. 


\subsection{Mainland Students Associations Overview}

History of the development of student clubs later, the first one was in 1920 by the student societies Deng Xia Peking University students and other established Marxism Research Society. Of community college students have gone through two peak periods, the first one is the "May Fourth" Movement, the second is after the 1980s. "May Fourth" before and after exercise, a time when fierce collision various trends of the period, literati Patriots efforts to explore the road of salvation, so at that time to establish and participate in student societies are mostly discussed in social thought and revolutionary practitioners, a relatively strong political overtones . In the late 1970s, along with the restoration of the college entrance examination system, a large number of young people who enter the university campus, student organizations then appeared in large numbers, to the mid-1980s, community hot culminated, community activities almost become the main form of student extracurricular activities, in an active campus culture and improve their overall ability to play an important role. "According to statistics, in 1986, Beijing, Wuhan, Anhui, students participate in community colleges and universities accounted for $30 \%$, respectively, $40 \%, 40 \%$ or more."

Since the 1990s, along with the gradual promotion of quality education and the CYL Central Committee and the Ministry of Education, the National Federation "Students' Quality Development Plan" is unfolding, the rapid development of community college students, community organizations the number, type and number of members have developed rapidly . 2002 CYL Central Committee, the Ministry of Education, the National Federation for the further implementation of the "CPC Central Committee and State Council on deepening education reform and the decision to promote quality education," the spirit to adapt to economic and social development of human resource development, especially young urgent need for human resource development, service quality Education for the full implementation of the majority of young students to adapt to growth and success, the urgent need for employment and entrepreneurship, some colleges and universities in the country to carry out "students' Quality Development Plan" pilot project, and in 2003 in full swing, the objective has greatly promoted the university the rapid development of student organizations. According to the Communist Youth League Central Committee and the China Youth Research Center in 2005, a survey showed that China's current total number of community college students in about 45,000 or so, the average has 20 colleges and universities; $59.7 \%$ of the students involved in the campus community, the average person involved in number of associations 1.8.

At present, in China the number of community college students showed increased scale, management increasingly sophisticated, the students gradually increased cohesion and influence the characteristics, but also showing a lot of new situations and new trends, one is academic, scientific and technological and comprehensive class societies, network societies increased, community activities and society, media contacts increased, interscholastic, extracurricular activities increased, reflecting the development of innovative societies. The other is the lack of scientific value-oriented, activity blindness and utilitarian and more prominent; internal management loose, lack of norms; lack of funds and the funds management and use of chaos; community continuity is poor, meaning and deep enough, repeat established phenomenon and so on. In response, many colleges and universities under the auspices of the Central Committee in strengthening student organizations work, Student Associations have been established in order to achieve self-management of student organizations, but the effect is still not ideal, can not fully meet the rapid development of the situation of student societies requirements.

\section{Hong Kong, Macao, Taiwan and the Mainland Differences in Community College Students}

Hong Kong, Macao, Taiwan and the mainland differences in community college students, the first is management, funding sources, such as different forms of organization, which also contributed to two different colleges and universities produce differences in function of the important reasons. Mainland student organizations mainly in the school committee established under the guidance Associations or Societies management center and generally by the person responsible, the school's student organizations are included in the Associations (or management center) unified management. Associations are responsible for various student organizations set up a preliminary review and report to the relevant departments for approval school. For student organizations to supervise and manage the daily work, such as student organizations responsible for the establishment, alteration or cancellation of the registration and filing of student organizations conduct annual inspection, violations of school regulations for student organizations on issues of supervision and inspection and processing. Through the organization of large-scale community activities enhancing their contacts and exchanges between communities for community development technology, information, and other resources to support . Despite the different universities in Mainland specific management of societies in different ways, but they are in the planning of these basic framework under. 


\subsection{The Characteristics of Hong Kong, Macao, Taiwan Community College Students}

Hong Kong and Macao college student organizations to improve their overall quality and service for students as the fundamental starting point, attention to student counseling for students through the provision of appropriate and high-quality service and support for students, and create a challenging and diverse learning environment to promote multifaceted round development of students and the growth of the students life-long learning, training for the community with self-confidence, a sense of justice, social responsibility and international perspective talent. Hong Kong and Macao college student organizations working to achieve the goals of higher education SAR mission, the students organize indirect management, and actively support the students creative activities to enrich campus life, student organizations have to play the role of the vast space independently. Hong Kong's community colleges and universities pay more attention to cultural and Halls Halls student organizations, the student residence halls opened into student education classroom to help students establish a sense of team, learn to get along with others practice.

Taiwanese university student organizations working in its "Ministry of Education" physical and moral, aesthetic five balanced education goals under the guidance of the student club activities as the focus of the work at all levels of school discipline has initiated normal leisure, love of Chinese culture, gregarious cultivate virtue, conservation service sentiment, temper academic research, cultivate leadership role. Taiwan's colleges and universities to promote university education is no longer overly elitist education, more attention to balanced development of education to help students establish a complete personality of the "all-round education." Thus, many universities and community activities as students will practice holistic education, the potential education, general education goals and ideals of the best way to spread in the school's various community activities, not only to university life colorful, but can develop interest broaden knowledge and develop social skills, hone leadership skills, promote university's overall educational function. Meanwhile, community activities so that students leave school a go, with rich social practice. Taiwanese college students in the community, with a wide range of people, benign operation, and develop a diversified characteristics.

Hong Kong, Macao and Taiwan are mostly college student societies and distinctive features, clarity of purpose and a large organization, with the following characteristics: First, the social mode of operation. Their student community management model, is often a microcosm of society, a high degree of social management. Second, standardized management system. Community colleges and universities have their purpose and create a strict charter, signed by the student officers will be reviewed and approved before implementation, although nominally under its Student Societies Officer will manage, but in fact the development community has great freedom and autonomy . Student officers will just played in the development of guidance on the direction of the role, does not directly interfere in the internal affairs of society. This makes the community and students closer together, but also to society and the Director-General will be closer to its broader space for development. Of a society Internally, president, vice president and other members of the Executive Committee and there is no strict distinction between. Third, schools and social forces support. School students to give full play to the role of associations in this second class provides the necessary basic conditions. Some colleges and universities for each community dedicated to open an online space for the community to create their own websites, but also for their nature, each community activity room provides fixed and corresponding venues in order to facilitate their activities, while providing the necessary equipment and funds. Student organizations in the community have a basic underlying support them private or non-profit organization, and many have established long-term partnership. There are many student clubs or organizations have registered as an official in the government's social groups.

\subsection{The Characteristics of Community College Students in Mainland}

Mainland Universities Student Association has initially formed a relatively complete some of the rules and regulations, such as "the rights and obligations of student societies," "community fund management system", "student organizations Responsibilities", "student assessment Member Societies Ordinance," etc. These rules and regulations with the relevant provisions of the education sector of societies from different levels of management were the norm. Such as "ordinary college student management regulations" require "students on campus organizations to participate in student groups, students formed groups, according to school regulations should apply in writing, at schools approved student groups should be in the Constitution, laws, regulations and school management activity within the system, to accept the school's leadership and management. "and each school on the management of student organizations have clear regulations, these regulations provide the institutional and community management associations operating mode. Communist Youth League organizations are generally business community college students in Mainland authorities, universities and student organizations to guide the Communist Youth League and being guided relationship. Its mode: student organizations directly affected by the 
school committee unified management, specifically belonging to the school Associations (HKCSS) direct guidance, developed by the Social Union specific activities and programs. Student Associations in the school under the leadership of the Communist Youth League student organizations responsible for managing the daily affairs of the body. The establishment of student organizations must first submit a written application to the Societies Federation, the Communist Youth League and reported to the school for approval, consent before recruiting members. Student organizations have some internal organizational structure, which is usually social (will) long under the corresponding work department or workgroup number, each working unit or working group is constituted by a number of members, members of Congress is the highest authority of community , the principle of democratic centralism is a community organization. Student organizations can be divided into school (hospital), the Department of two. Main cadres of student organizations responsible for inspection by the Associations, Societies cadres should be high academic achievers, enthusiastic community work, with a strong ability to work and a strong mass base. Development at all levels of society according to their need to charge membership fees, charged at the standard shall obtain the approval of the competent authorities, shall establish a complete management fee income and expenditure account .

Mainland, the main purpose of community college students stay in the richness and functional campus life, students hobbies, and participate in school activities, expanding the field of knowledge, to increase the scope of dating, rich inner world and other levels. While focusing on strengthening the scientific spirit and humanistic quality education, well-organized cultural activities on campus, to carry out rich content and form of new, attractive and strong ideological education, academic science and technology, cultural and sports activities such as campus culture, the moral, intellectual, physical, aesthetic infiltrate campus cultural activities among the students in the activities of benefit . Meanwhile, the mainland community college students also formed its own characteristics and advantages, train and bring up a number of outstanding student leaders. College students and community activities Mainland mechanism makes part of their postgraduate academic strengths better play, student exchanges more common, more general network resources more mature use .

\section{Issues, Experiences and Inspiration}

Because systems, culture, history and other factors, Hong Kong, Macao, Taiwan and the mainland compared to community college students, there are many different. Community college students through Hong Kong, Macao, Taiwan and the mainland student societies comparison community college students in the study of the problems facing the development, you can provide each other with experience and methods, thus contributing to Hong Kong, Macao, Taiwan and mainland joint development of community college students. Student organizations are not perfect, there are many negative factors, which requires us to face the Mainland and Hong Kong, Macao, Taiwan community college students lack of community college students. Through the above comparative study, we find that, compared with Hong Kong, Macao, Taiwan's community colleges and universities, student organizations Mainland guiding philosophy of working either in or in practice there is a certain lack of urgent further strengthened.

\subsection{Problems}

\subsubsection{Participation in Society Motives, the Actual Effect Is Poor}

In the university community management can easily arise in two extremes is a student club activities and the imbalance between learning and student participation in extracurricular activities too social motivation. The first phenomenon is the community members based on the same interests and hobbies, tend to learn lessons aside and blind to participate in some of the communities to go, engrossed in community activities, participation in community activities and the resulting imbalance between learning, performance plummeted. Another phenomenon is the motivation too utilitarian, direct, founder of the purpose is to enrich community college life, cultivate students' comprehensive ability, but with the continuous development of market economy, market concept also continue to impact people's values. Some students to participate in community activities, are more concerned about personal interests, concerns participate in extracurricular activities plus the comprehensive evaluation of beneficial activities without concern whether it makes sense, with serious utilitarian overtones.

\subsubsection{Is Not Standardized, the Lack of Scientific, Humane Management System}

Community management is a complex systems engineering, is also an art, very particular about the management methods and techniques. The reason why the Hong Kong community colleges and universities do a great success, which comes from the advanced management mechanism and operation mode, each community has its own purpose and create strict charter, signed by the student officers will be reviewed and approved before implementation, because of its own is an independent legal entity, if the member to withdraw because of dissatisfaction with the fate will be a direct result of community, which makes the relationship between members 
and the community more closely. Community college students compared to the mainland part of the internal management of confusion, not strictly regulate the constitution, ignoring members and community spirit contact, not in the interests of our members. Meanwhile, some schools supported by administrative bodies, student organizations, lack the necessary guidance and guidance, there is no unified management system, resulting in some societies nominal.

\subsubsection{Single Active Content, Innovation Ability and Not Attractive Enough}

Although community variety in colleges and universities, involving eight class community types, but specific to certain activities tend to appear content boring, a single, and so on and so forth. Such as give priority to in order to develop science and technology innovation ability of technology student community on the quantity and quality also is very limited, club activities lack of innovation, content of dogma. While some literary arts community due to insufficient attraction activities, club activities, community activities, form a single, lack of characteristics level is not high, causing many members basically out of from the state. Exist from the perspective of the contents of club activities, through the motions, such as some of the sports community just took the membership to some sports activities, organize collective activity, one or two times no deep content, lack of communication between members, meaning is not big.

\subsubsection{A Single Source of Funding, Social Functioning Level Is Not High}

Because society is mainly funded grants and membership dues from school two aspects, and in order to encourage the community scale, collect dues rarely, most community activities are present inadequate funding phenomenon, which led directly to the effects of community activities. Many of the activities of student organizations is dependent on sponsorship money, but because the student experience and energy are limited, sponsorship with a lot of uncertainty, and too easy. Compared with Hong Kong, Macao and Taiwan universities, community colleges and universities in the Mainland is not high functioning pervasive social problem, commercial operation mode much, too dependent on school funding allocations, funding sources and the lack of investment in community colleges and universities for students with Hong Kong, Macao and Taiwan Universities gaps.

\subsection{Experience and Inspiration}

\subsubsection{To Establish a Relatively Stable Community Cadres Team}

For one group, the outstanding leadership team is undoubtedly the most important, and therefore, it is necessary scientific selection, careful cultivation, improve community is the backbone of the student leaders, especially the overall quality and effectiveness of leadership on the important role of community work. At present, although the general university community Associations specific co-ordination by the school, but the community is relatively independent, autonomous extracurricular activities often lack an overall outstanding community cadres training and selection. Community development and community leaders have a great overall quality of contact, must pay attention to the training of cadres of societies and guidance offered through cadre training, outdoor development, community activities and other forms of exchange of experience, the person in charge of societies systematic training, the main student organizations and cadres into the assessment, reward and punishment mechanism, establish relevant accountability mechanisms, the latter shall be removed by the ranking events eligibility.

\subsubsection{The Implementation of More Scientific and Humane Forms of Organization and Management Mechanisms}

Scientific management is the basis for healthy functioning of society, humane society mechanisms to maintain a constant source of development. The success of the Hong Kong community college experience shows that only by constantly improving student club management system construction, a clear management responsibilities, develop a standardized university community management approach in order to ensure the healthy development of community activities. Management system includes not only its own charter, regulations, financial systems, etc., should also include management's responsibilities, incentives, monitoring mechanisms, advocacy mechanisms. At the same time, adhere to the student-oriented, respect for community self-management, self-service, self-development under the premise of the majority of members to actively carry out the activities required to respect the needs and requirements of the general membership, through the General Assembly and other forms of community activities to develop the plan, rather than by several student leaders decided to form community activities to enforce.

\section{2 .3}

Build community features, innovative activities. Subjectivity college student organizations are playing an important carrier of the development potential of students, a stage to show themselves, but also the prosperity of campus culture, an effective platform for a strong academic atmosphere. Community activities attractive or not 
directly affect the quality and influence, only the active content and form of constant innovation in order to meet students from radically growing spiritual and cultural needs. Therefore, efforts should be made to expand community participation in activities face, build community features to attract more students to participate in student clubs and extracurricular activities. Societies should explore the establishment of certain internal demands and supervision mechanism, through joint meetings and other forms of associations to mobilize broad membership of initiative and creativity, brainstorming, so that the activities to make the brand, to make features, making results.

\subsubsection{To Expand Funding Sources, and constantly Enhance the Degree of Social Functioning}

Associations to carry out all the activities financed basic protection, Hong Kong, Macao and Taiwan universities operate on the source of funding is relatively mature, so carry effect is obvious. In contrast, most of our colleges and universities in the source of funding is relatively simple, the limited amount of funds, under the present conditions, the school actively seek policy on the one hand, due to increase in financial support, through established between universities and enterprises more forms long-term and stable cooperative relationship for student organizations access to relevant resources. While the other student organizations should be encouraged to actively use professional advantages and team strengths organize various social services, access to social and corporate sponsors, and actively carry out social work. In addition, schools should encourage students to take the business community patterns, from a mere "blood" to "blood" way to change, laboratories and other entities through entrepreneurship, so that gradually become an administrative appropriations mainly dependent on voluntary activity, self-financing organizations, free services and paid services through a combination of funding sources to achieve multi-source community.

\section{Conclusion}

In this study, we adopted Hong Kong, Macao, Taiwan and the Mainland College Student Association Student Association comparative analysis, summed up some of the existing problems, such as management is not standardized, single source of funding, lack of teamwork, etc., through the comparative study, we also derive obtained some experience and enlightenment, it is relevant to establish accountability mechanisms, humane forms of organization and management mechanism, enhance the level of social functioning, strengthen risk awareness, through exploring some have referential significance of new theories and new ways of promoting the healthy development of higher education under the new situation.

\section{References}

Chen, S. W. (2009). Community colleges and universities should be managed to avoid two extremes. Technology Information, 18.

Gao, C. M., \& Y. H., W. (1999). Knowledge Smart. Creating quality education engineering campus culture book stacks (p. 284). Beijing: Economic Daily Press.

Guo, J. (2009). About the university community building Suggestions. Science aspect, 5.

Hao, W. (2008). On the self-development of university community members and the community cohesion. Shanxi Education, 10.

Yu, W., \& H, L. Y. (2002). American College Student Association Cultural Comparative Study on Several Issues. Foreign Education, 10.

Zhu, F. (2008). Hong Kong university student organization status, operational and inspired by the Mainland Universities (Vol. 2). Guangxi Youth Leaders College.

Zhu, R. X. (2002). Hong Kong university students' affairs management implications. Higher Education of Engineering, 4.

\section{Copyrights}

Copyright for this article is retained by the author (s), with first publication rights granted to the journal.

This is an open-access article distributed under the terms and conditions of the Creative Commons Attribution license (http://creativecommons.org/licenses/by/3.0/). 